MacPherson as Senior Assistant Officer, and Dr. Elkins had been appointed Junior A ssistant.

On the motion of the Lord Provost, Dr. Clouston was cordially thanked for his interesting report.

\title{
CHANGES IN THE IRISH LUNACY BOARD.
}

RESIGNATIONS OF DRS. NCGENT AND HATCHELL.

We believe that Dr. (now Sir) John Nugent was appointed Inspector of Lunatic Asylums in Ireland in 1847. The period covered is, therefore, fortytwo years, possibly an unprecedented record of official work.

Dr. George W. Hatchell was appointed to the office early in 1857. In the fourth volume of this Journal will be found a notice of his appointment, and the feeling it elicited at that time.

THE NEW INSPECTORS OF LUNATIC ABYLCMS.

It has been known for some time that the vacancies caused by the resignation of Dr. Hatchell, which is understood to have occurred about a year ago, and of Dr. Nugent, which is a more recent event, were about to be filled up by the appointment of Drs. Plunkett O'Farrell and Maziere Courtenay. The long delay that has occurred in connection with these appointments is believed to be in part due to the fact that the Chief Secretary was awaiting the reports of the Departmental Commission, presided over by Sir Arthur Mitchell, which was deputed several months ago to examine into certain questions connected with the administration of the Irish lunacy department.

The new Inspectors are men of high professional character, of whom much is hoped. They are almost contemporaries. Both are distinguished alumni of the Dublin University. Dr. O'Farrell's college career was unusually brilliant. He obtained First Senior Moderatorship with his Arts Degree, and is a Gold Medallist in Natural and Experimental Science. Besides minor honours in the School of Physic, he received the Medical Travelling Prize when taking out his M.B. degree in 1869. Dr. Courtenay took the first place at his M.B. examination in 1871. As a student, he was perhaps the best-known and most popular man of his generation in Trinity College. Of the host of friends he then made many have already gone over to the majority, but not a few are left to congratulate him on his well-earned promotion. Some of the "old set" will also recollect with satisfaction that both the new Inspectors were educated at a famous old Dublin hospital (the Richmond), now unhappily threatened with extinction.

George Plunkett O'Farrell, M.D, gazetted Inspector of Lunatic Asylums, January, 1890, was up to the date of this appointment Medical Member of the Irish General Prisons Board, and Inspector of Reformatories and Industrial Schools. He formerly held the office of Local Government Board Inspector for the important district of Cork. Previously he had enjoyed a good provincial practice at Boyle, co. Roscommon, where he succeeded his father, the late Dr. O'Farrell.

Though Dr. Plunkett O'Farrell has unfortunately not had any special experience of insanity and asylum administration, his appointment is one that has met with very general approval, and, admitting the peculiar difficulties that hamper the Irish Government in filling vacancies in the public service, is probably the best that could be made. He has a considerable and a varied experience of official work, and he is undoubtedly an able and cultivated man.

Edward Maziere Courtenay, M.D., gazetted Inspector of Lunatic Asylums, March, 1890, is well known to many members of the Medico-Psychological 
Association, having been for several years Irish Secretary. Dr. Courtenay has passed through a full apprenticeship in our specialty. He was Clinical Assistant at the West Riding Asylum, and subsequently was Assistant Medical Officer at the Derby Asylum, Mickleover. Since June, 1873, he has been Medical Superintendent of the Limerick District Asylum. His administrative work there was of a very high order. The condition of excellence to which he had brought that institution renders it at present comparable-and in some respects favourably comparable - with a good English or Scotch asylum. The energy and ability that this connotes must be evident to those who know what Irish asylums are, and what the difficulties are which in that country surround the work of such a reformer as Dr. Courtenay.

Dr. Courtenay's appointment has received an approval almost universal.

The Irish Government is to be congratulated on having shown in Dr. Courtenay's case not only special recognition of distinguished merit, but an openness of mind which has enabled it to see merit even in an asylum physician, and a magnanimity which has led to a choice being made from among a comparatively friendless and uninfluential body of specialists, instead of, in the ordinary way, from among the politicians. The ice has been broken. Dr. Courtenay is the first asylum superintendent who has ever been made an Inspector, and the first Inspector since the now forgotten Dr. White, dead nearly half-a-century, who had even a claim in courtesy to be called an asylum officer.

The new Inspectors have a big task before them-nothing less than the entire reorganization of their department. It is a task that will require patience, tact, unwearying industry, and unwavering courage. Both are young men, both have shown themselves energetic men. They come to their new work fortified with the prestige of success, and nerved by the knowledge of the high esteem in which they stand with the profession and the public. We wish them God-speed, and we are confident we shall not be disappointed in expecting from them such work as will redeem the character of the Irish asylums, and will, with the co-operation of the Irish resident physicians, bring our specialty, hitherto so much neglected in Ireland, to the same level to which it has attained elsewhere in Europe and America.

TENTH INTERNATIONAL MEDICAL CONGRESS, BERLIN, 1890. INVITATION TO THE INTERNATIONAL MEDICO-SCIENTIFIC EXHIBITION, BERLIN, AUGUST, 1890.

In connection with the Tenth International Medical Congress, to be held in Berlin, August 4th-9th, 1890, there will be an International Medico-Scientific Exhibition.

The undersigned Committee of Organization has been authorized, by the representatives of the medical faculties and leading medical societies of the German Empire, to make the preliminary arrangements. We therefore cordially invite all who may wish to exhibit or participate in the above Exhibition; all exhibits, however, to be of a scientific nature.

The exhibits expected will be as follows :-

1. New or improved scientific instruments for biological and special medical purposes, including apparatus for photography and spectral analysis pertaining to medicine.

2. New pharmacological chemical substances and preparations.

3. New pharmaceutical substances and preparations.

4. New food preparations.

5. New or improved instruments for internal and external medicine, and allied specialties, including electrotherapy.

6. Plans and models (new) of hospitals, houses for reconvalescents, disinfection, and general bath-houses. 